\title{
Health Benefits and Cost-Effectiveness of Brief Clinician Tobacco Counseling for Youth and Adults
}

\author{
Michael V. Maciosek, $P b D$ \\ Amy B. LaFrance, MPH \\ Steven P. Debmer, PbD \\ Dana A. McGree \\ Zack Xu, MS \\ Thomas J. Flottemesch, PbD \\ Leif I. Solberg, MD \\ HealthPartners Institute, Minneapolis, \\ Minnesota

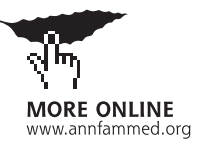

Conflicts of interest: authors report none.

\section{CORRESPONDING AUTHOR}

Michael V. Maciosek, PhD

HealthPartners Institute

Mailstop 23301A

PO Box 1524

Minneapolis, MN 55440-1524

michael.v.maciosek@healthpartners.com

\begin{abstract}
PURPOSE To help clinicians and care systems determine the priority for tobacco counseling in busy clinic schedules, we assessed the lifetime health and economic value of annually counseling youth to discourage smoking initiation and of annually counseling adults to encourage cessation.
\end{abstract}

METHODS We conducted a microsimulation analysis to estimate the health impact and cost effectiveness of both types of tobacco counseling in a US birth cohort of 4,000,000. The model used for the analysis was constructed from nationally representative data sets and structured literature reviews.

RESULTS Compared with no tobacco counseling, the model predicts that annual counseling for youth would reduce the average prevalence of smoking cigarettes during adult years by 2.0 percentage points, whereas annual counseling for adults will reduce prevalence by 3.8 percentage points. Youth counseling would prevent 42,686 smoking-attributable fatalities and increase quality-adjusted life years (QALYs) by 756,601 over the lifetime of the cohort. Adult counseling would prevent 69,901 smoking-attributable fatalities and increase QALYs by 1,044,392. Youth and adult counseling would yield net savings of $\$ 225$ and $\$ 580$ per person, respectively. If annual tobacco counseling was provided to the cohort during both youth and adult years, then adult smoking prevalence would be 5.5 percentage points lower compared with no counseling, and there would be 105,917 fewer smoking-attributable fatalities over their lifetimes. Only one-third of the potential health and economic benefits of counseling are being realized at current counseling rates.

CONCLUSIONS Brief tobacco counseling provides substantial health benefits while producing cost savings. Both youth and adult intervention are high-priority uses of limited clinician time.

Ann Fam Med 2017;15:37-47. https://doi.org/10.1370/afm.2022.

\section{INTRODUCTION}

dult smoking prevalence fell 2 percentage points from 17\% in 2014

A to $15.3 \%$ in 2015 (age adjusted). ${ }^{1}$ Yet 42 million adults continue to smoke, $^{2}$ and in 2015, 1.6 million middle- and high-school students self-reported smoking tobacco in the last 30 days. $^{3}$ A 2014 Surgeon General's report summarizing 50 years of progress in the fight against smoking noted that smoking is still the leading cause of preventable death in the United States and that the direct medical costs of smoking are about $\$ 175$ billion per year. ${ }^{2}$

In 2015, the US Preventive Services Task Force (USPSTF) reaffirmed its long-standing, evidence-based recommendation that clinicians ask adults about tobacco use, provide advice to stop, and offer smoking cessation medications. ${ }^{4}$ In adults, brief, one-time counseling alone may increase cessation rates by 2 percentage points, and by 5 to 16 percentage points when adults use smoking cessation medications. ${ }^{4,5}$

On the other hand, counseling youth to prevent initiation might yield even greater benefits than counseling adults to quit. Former smokers remain at some risk for smoking-attributable disease; therefore, primary 
prevention of tobacco use through youth counseling may yield greater benefits long-term. Evidence supporting clinical interventions to prevent youth initiation has lagged behind that for adult cessation counseling. In 2003, a USPSTF review concluded there was insufficient evidence to recommend for or against routine screening to prevent smoking initiation by youth. ${ }^{6}$ In 2013 new evidence ${ }^{7}$ resulted in a USPSTF recommendation that primary care clinicians provide education or brief counseling to prevent initiation of tobacco use in school-aged children and adolescents. ${ }^{8}$ Such counseling reduces youth initiation by 2 percentage points. ${ }^{7,8}$

Although counseling and smoking cessation medications are effective, the impact of repeatedly offering counseling and assistance has not been evaluated in controlled studies. Health benefits and cost reductions are likely to start years after counseling for adults and decades after counseling for youth. Hence, no direct health benefits have been observed in studies. Even though the long-term health and economic impact of repeated cessation counseling for adults has been assessed in simulation models, ${ }^{9,10}$ the impact of counseling youth to discourage initiation of cigarette smoking has not; neither has the combined lifetime impact of counseling youth that was followed up by encouraging cessation among those who still become adult smokers.

Assessing the complete benefits and costs of tobacco cessation counseling is essential to determine its priority among competing demands on clinic time. Tobacco counseling competes with treatment of acute symptoms, management of multiple chronic diseases, and other preventive services, as well as suggestions to integrate clinical practice with community health organizations and to coordinate with community health workers to address patients' social determinants of health. ${ }^{11-20}$ Yarnall and colleagues estimated that a physician with a panel of 2,500 patients would need 7.4 hours per day to deliver evidence-based preventive services ${ }^{21}$ and as many as 10.6 hours to provide disease management for chronic conditions. ${ }^{22}$ Though Altschuler et al estimated that a physician could care for a panel of 2,000 patients with the maximum feasible delegation of preventive services and chronic disease care to other primary care team members, ${ }^{23}$ that level of delegation may be a long time coming.

To help clinicians and care systems better understand tobacco counseling's priority among the competing demands on physician time, we simulated the long-term value of providing brief, annual tobacco intervention during both youth and adult years over the lifetimes of a US birth cohort.

\section{METHODS}

We simulated scenarios with and without the brief tobacco interventions recommended by the USPSTF for youth and adults using the HealthPartners Institute ModelHealth: Tobacco microsimulation model, which was constructed in TreeAge Pro 2014 R2.0 (TreeAge Software, Inc) to evaluate the impact of clinic- and community-based interventions to reduce cigarette smoking. The analysis follows the methodology chosen by the National Commission on Prevention Priorities (NCPP) for the accompanying ranking of clinical preventive services (Prevention Priorities). ${ }^{24}$ Prevention Priorities is based on 2 metrics: clinical preventable burden and cost-effectiveness. Clinical preventable burden measures the health impact of offering a clinical service to $100 \%$ of the target population in undiscounted quality-adjusted life years (QALYs) saved. Cost-effectiveness is measured as discounted net costs per discounted QALY gained when net costs are positive $_{;}$it is measured as costs saved per person in a birth cohort when net costs are negative. Here we report clinical preventable burden and cost-effectiveness along with smoking-attributable disease events, fatalities, and medical costs prevented.

For constancy across services assessed for the accompanying ranking of clinical preventive services, ${ }^{24}$ all costs were adjusted to year 2012 US dollars, and costs and QALYs were discounted to present value at $3 \%$ per year in calculating cost-effectiveness. ${ }^{25}$ QALYs are not discounted in the calculation of clinical preventable burden.

\section{Intervention Scenarios}

For Prevention Priorities, ${ }^{24}$ we separately estimated annual youth counseling and annual adult counseling intervention scenarios and compared them with no provision of counseling for the corresponding agegroup. In keeping with the evidence, youth counseling is limited to the impact on preventing initiation. Adult counseling is focused on encouraging cessation through the 5As (ask about tobacco use, advise to quit, assess willingness to quit, assist with quit, and arrange follow-up), ${ }^{26}$ including smoking cessation medications. We describe how these intervention scenarios were implemented in the model.

For context, we assessed a third scenario of youth and adult counseling, which reflects the complete impact of first counseling youth to prevent initiation and subsequently counseling those who become adult smokers to quit. We compare this scenario with the counterfactual no-counseling scenario to estimate the combined impact of youth and adult counseling compared with providing no counseling. We also compared this combined service with a current delivery rate 
scenario to estimate the potential impact of increasing delivery of lifelong counseling.

\section{Microsimulation}

We conducted ModelHealth: Tobacco simulations that began with a cohort of children aged 8 years representative of the US population in terms of sex and race-ethnicity. When the cohort reaches age 25 years during the simulation, lifetime education level is assigned according to the educational attainment of today's adults aged 25 years. ModelHealth: Tobacco is described in detail with all model parameters in the Supplemental Appendix, available at http://www. annfammed.org/content/15/1/37/suppl/DC1. The model simulates the lifetime impact of cigarette smoking on health and economic outcomes. Simulated individuals begin as never smokers at age 8 years. Multivariate risk equations based on the Youth Behavior Risk Survey ${ }^{27}$ and the National Health Interview Survey ${ }^{28}$ determine the probability that they will become smokers each year, and if they do, the probability that they will become former smokers in subsequent years.

The incidence of smoking-attributable disease events was derived from the Surveillance, Epidemiology, and End Results (SEER) Program of the National Cancer Institute, ${ }^{29}$ the National Hospital Discharge Survey, ${ }^{30}$ and compressed mortality files. ${ }^{31}$ Total disease events by smoking status are derived by applying sex-specific smoking-attributable relative risks for 10 cancers, 6 cardiovascular disease categories, and 3 respiratory diseases obtained from SmokingAttributable Mortality, Morbidity, and Economic Costs (SAMMEC), an online resource maintained by the Centers for Disease Control and Prevention for estimating the burden of cigarette smoking. ${ }^{32}$ Additional detail on the calculation of QALYs, including event rates, event duration, and health utilities, are provided in the Supplemental Appendix.

We estimated medical costs by smoking status in linked Medical Expenditure Panel Survey (MEPS) and National Health Interview Survey (NHIS) data ${ }^{33}$ according to the method of Levy and Newhouse. ${ }^{34}$ MEPS and other claims data, however, show that former smokers have higher health care expenditures than current smokers, perhaps because quits are frequently triggered by symptoms of smoking-related disease ${ }^{35-40}$ Hence, estimates derived from claims data overstate the costs of former smokers who quit with counseling before the onset of smoking-attributable disease. We therefore estimated the costs of former smokers with an exponential function (described in the Supplemental Appendix) that defines the difference in risk between current and former smokers in relation to time since quit.

\section{Effectiveness in Counseling Scenarios}

To obtain an estimate of effectiveness for youth counseling, we reviewed studies identified in the USPSTF systematic review. ${ }^{7}$ We excluded 3 studies $^{41-43}$ because their measures of youth smoking were inconsistent with those in the simulation model. We excluded another study ${ }^{44}$ because the tobacco intervention was just 1 aspect of an intensive intervention that targeted a range of substance abuse and sexual health behaviors. Among the remaining 6 studies $^{45-50}$ the average relative risk for initiation among youth who received counseling was 0.80 compared with no- or minimalintervention control groups.

In the simulation, smoking is reduced through increased receipt of brief counseling and cessation medications. ModelHealth: Tobacco assigns smokers to 1 of 6 quit strategies: no assistance, brief counseling alone, over-the-counter nicotine-replacement therapy, prescription nicotine-replacement therapy with brief counseling, bupropion with brief counseling, or varenicline with brief counseling. With brief cessation counseling provided to all smokers, the $51 \%$ of smokers who would have tried to quit without clinician advice are reassigned to 1 of the other 5 quit strategies in proportion to the uptake of that strategy in the current US population. ${ }^{51}$ The success of quitting with counseling and medication was determined by the relative risk of cessation compared with no assistance. We obtained the relative risk of cessation when using nicotinereplacement therapy, bupropion, and varenicline compared with placebo (relative risk $[R R]=1.60,1.69$, and 2.27 , respectively) from a network meta-analysis. ${ }^{52}$ The effectiveness of brief counseling alone was based on the median relative risk $(\mathrm{RR}=1.32)$ of cessation compared with no intervention among 13 studies in our previous review and 1 additional study published since then., ${ }^{9,53}$

\section{No Counseling (Counterfactual) Scenarios}

Constructing counterfactual scenarios of an environment without counseling required careful consideration. Available data suggest that the frequency of anti-initiation counseling for youth is very low. Most nationally representative frequencies of clinician counseling for youth are based on the National Hospital Ambulatory Medical Care Survey (NHAMCS) and the National Ambulatory Medical Care Survey (NAMCS), for which providing any information about tobacco counted as counseling, and encouraging abstinence was not distinguished from encouraging cessation. ${ }^{54}$ Based on these surveys, Rand et al reported that tobacco use was discussed in $13.3 \%$ of well visits and $8.5 \%$ of acute illness visits for patients aged 11 to 21 years from 1997 to $2000 .{ }^{55}$ Based on NAMCS, Jamal et al reported that screening for tobacco use occurred in $70 \%$ of office vis- 
its for patients aged 11 to 21 years during 2004 to 2010, but assistance for cessation was provided in only $20 \%$ of smokers' visits. ${ }^{54}$ Because nationally representative estimates of counseling to prevent initiation are not available, and the limited data on youth counseling indicate it is uncommon, we assumed that current youth smoking patterns approximate no counseling, and we used the current delivery scenario as the counterfactual to represent no youth counseling. Counseling to encourage adult cessation is common. ${ }^{51,56,57}$ We therefore created a no-cessation counseling scenario for adults by assigning all smokers to the no-assistance quit strategy.

\section{Counseling and Medication Costs}

The costs of annual counseling used in the analysis were $\$ 35$ for youth and $\$ 26$ for adults, including the cost of patient or parent time. We applied costs consistently across preventive services in the ranking. ${ }^{24}$ Youth counseling costs reflect 1 minute of brief antitobacco use message from a physician and 20 minutes with a health educator, based on averages among the 6 studies represented in the effectiveness estimate. ${ }^{45-50}$ We added $\$ 5$ per patient for printed educational materials or computerized information. We simplified the implementation of adult counseling costs in the model by assigning all patients 3 minutes of clinician time for assessing tobacco use and counseling. Nonsmokers (more than $80 \%$ of visits) will require much less time, and smokers interested in quitting with a smoking cessation medication and willing to arrange follow-up will require more. Although the average time should fall with decreased smoking prevalence, this effect is not accounted for in the simulation.

We valued physician time as the portion of a 15 -minute office visit $\left(1 / 15^{\text {th }}\right.$ for youth and $3 / 15^{\text {th }}$ for adults) using the average of Medicare reimbursement and $75 \%$ of the median private sector charge. ${ }^{58}$ Health educator time is valued using the average hourly earnings for Bureau of Labor Statistics occupation code 21-1091, ${ }^{59}$ plus an additional 50\% for employee benefits and overhead. Finally, following the reference case methods of the Panel on Cost-Effectiveness in Health and Medicine, ${ }^{25}$ we include patient time for adults and parent time to accompany youth. For patient or parent time, we assume a visit takes 2 hours including travel, but we attribute only a portion to tobacco counseling, based on the number of minutes of a 15 -minute visit spent on tobacco counseling. Patient time was valued using average hourly earnings of $\$ 31$ per hour in 2012. ${ }^{60}$

The costs of over-the-counter nicotine-replacement therapy (\$190), prescription nicotine-replacement therapy $(\$ 790)$, bupropion $(\$ 181)$, and varenicline $(\$ 826)$ were determined from a convenience sample of online prices for the recommended 90-day treatment (www. cvs.com, www.drugs.com, www.goodrx.com, www. walmart.com, www.target.com). Over-the-counter nicotine-replacement therapy was priced as the average of patches and gum and assumed an equal mix of generic and brand use. We assumed $95 \%$ of bupropion use was generic and 5\% was branded Zyban because of the large difference in price. Prescription nicotinereplacement therapy (Niotrol inhaler) and varenicline (Chantix) were priced at their respective brands, because no generics are available. In the model, those with an unsuccessful quit attempt faced a portion of these costs, which varied randomly to reflect different quit attempt durations.

\section{Sensitivity Analysis}

In Prevention Priorities, estimates of clinical preventable burden and cost-effectiveness are based upon a variety of sources ranging from literature-based estimates to detailed microsimulations. ${ }^{24}$ We planned sensitivity analysis to produce ranges of estimates that can be compared across preventive services regardless of the source of the clinical preventable burden and cost-effectiveness estimates. We first conducted single-variable sensitivity analysis. A single variable may encompass aggregates, such as changes to all quality-of-life weights at 1 time in the same direction. Then, we estimated a plausible range of upper and lower values for clinical preventable burden and costeffectiveness by combining the 2 to 3 most influential variables (depending on use of aggregates).

\section{RESULTS}

The model predicted that counseling youth will result in an additional 756,601 QALYs over the lifetime of a birth cohort of $4,000,000$ people, ${ }^{61}$ with net discounted cost-savings of $\$ 225$ per person. Adult counseling will produce 1,044,392 QALYs, with net savings of $\$ 580$ per person (Table 1). Before discounting, the costs of counseling youth aged 9 to18 years is similar to the combined costs of cessation counseling and smoking cessation medications for adult smokers (not shown), but discounting to present value results in adult counseling costs being substantially lower.

The combined youth and adult counseling scenario produced less benefit than the sum of its parts because youth counseling reduces the number of adult smokers who could benefit from cessation counseling (Table 2). The marginal analyses indicated that only about onehalf of the benefit of adult counseling and one-third of the benefit of adult and youth counseling combined would be realized if current counseling rates continue.

The 4 panels in Figure 1 illustrate the lifetime patterns that underlie these results. Figure 1 shows the 
Table 1. Health Impact and Cost-Effectiveness of Brief Tobacco Counseling in a US Birth Cohort of 4,000,000: Clinical Preventive Service Priorities Estimates

\begin{tabular}{lcc}
\hline & $\begin{array}{c}\text { Youth Counseling } \\
\text { vs No Youth } \\
\text { Counseling }\end{array}$ & $\begin{array}{c}\text { Adult Counseling } \\
\text { vs No Adult } \\
\text { Counseling }\end{array}$ \\
\hline $\begin{array}{l}\text { Change in years lived as smokers, No. } \\
\text { Change in adult smoking prevalence }\end{array}$ & $-4,971,393$ & $-8,458,331$ \\
(weighted by cohort size at each age), \% & -2.0 & -3.8 \\
$\begin{array}{l}\text { Change in years lived as former smokers, No. } \\
\text { Change in smoking-attributable cancers, No. }\end{array}$ & $-8,140,126$ & $-14,679$ \\
$\begin{array}{l}\text { Change in smoking-attributable CvD hospi- } \\
\text { talizations, No. }\end{array}$ & $-9,925$ & $-176,045$ \\
Change in smoking-attributable respiratory \\
disease hospitalizations, No.
\end{tabular}

ing were provided to all adults, prevalence would peak at $16.8 \%$. If counseling to reduce initiation were provided during youth and followed up with cessation counseling for smokers during adulthood, the predicted peak prevalence would be only $13.7 \%$. Averaged over all adult years, prevalence would be $2.0,3.8$, and 5.5 percentage points lower with youth-only counseling, adultonly counseling, and combined youth and adult counseling, respectively.

Consistent with the inputs from SAMMEC, the model does not assign smoking-attributable disease or medical costs before age 35 years. Figure 1 shows how, under this assumption, preventing early smoking-attributable fatalities increases late-age fatalities. Lifetime smokingattributable fatalities of the birth

prevalence of current smoking over the cohort's lifetime under each scenario. The model predicts smoking prevalence will peak at $20.7 \%$ at age 25 years without counseling. At current rates of cessation counseling, peak smoking prevalence reduces to $18.5 \%$. If counseling against initiation were provided to all youth, prevalence would peak at $15.5 \%$. If cessation counsel- cohort, however, are still reduced by counseling, and QALYs gained remain positive at all ages (Figure 1) because more individuals are alive at all ages. Figure 1 illustrates how the initial youth counseling costs are eventually offset by reduced smoking-attributable expenditures. Adult counseling and medication costs are incurred later and are spread more evenly through

Table 2. Health Impact and Cost-Effectiveness of Brief Tobacco Counseling in a US Birth Cohort of 4,000,000: Supplemental Analyses

\begin{tabular}{|c|c|c|c|}
\hline Effect & $\begin{array}{l}\text { Youth and Adult } \\
\text { Counseling vs } \\
\text { No Counseling }\end{array}$ & $\begin{array}{l}\text { Adult Counseling } \\
\text { vs Current } \\
\text { Delivery Rates }\end{array}$ & $\begin{array}{c}\text { Youth and Adult } \\
\text { Counseling vs Current } \\
\text { Delivery Rates }\end{array}$ \\
\hline Change in years lived as smokers, No. & $-12,575,864$ & $-4,391,547$ & $-8,509,081$ \\
\hline $\begin{array}{l}\text { Change in adult smoking prevalence (weighted by cohort } \\
\text { size at each age), \% }\end{array}$ & -5.5 & -2.0 & -3.6 \\
\hline Change in years lived as former smokers, No. & 408,378 & $4,903,772$ & $-214,198$ \\
\hline Change in smoking-attributable cancers, No. & $-23,279$ & $-7,142$ & $-15,741$ \\
\hline Change in smoking-attributable CVD hospitalizations, No. & $-259,128$ & $-81,087$ & $-164,171$ \\
\hline $\begin{array}{l}\text { Change in smoking-attributable respiratory disease hospitaliza- } \\
\text { tions, No. }\end{array}$ & $-290,432$ & $-82,475$ & $-193,206$ \\
\hline Change in smoking-attributable fatalities, No. & $-105,917$ & $-33,189$ & $-69,205$ \\
\hline Change in QALYs saved, undiscounted, No. & $1,637,648$ & 512,225 & $1,105,481$ \\
\hline $\begin{array}{l}\text { Change in counseling and cessation medication costs, } \\
\text { discounted, \$ millions }\end{array}$ & 1,324 & 91 & 988 \\
\hline $\begin{array}{l}\text { Change in smoking-attributable medical costs, discounted, } \\
\$ \text { millions }\end{array}$ & $-4,278$ & $-1,444$ & $-2,977$ \\
\hline Change in total costs, discounted, $\$$ millions & $-2,955$ & $-1,353$ & $-1,989$ \\
\hline Cost-effectiveness: discounted net costs per person, $\$ /$ person & -739 & -338 & -497 \\
\hline
\end{tabular}


Figure 1. Lifetime effects of tobacco counseling vs no counseling in a US birth cohort of 4,000,000.

US Smoking prevalence

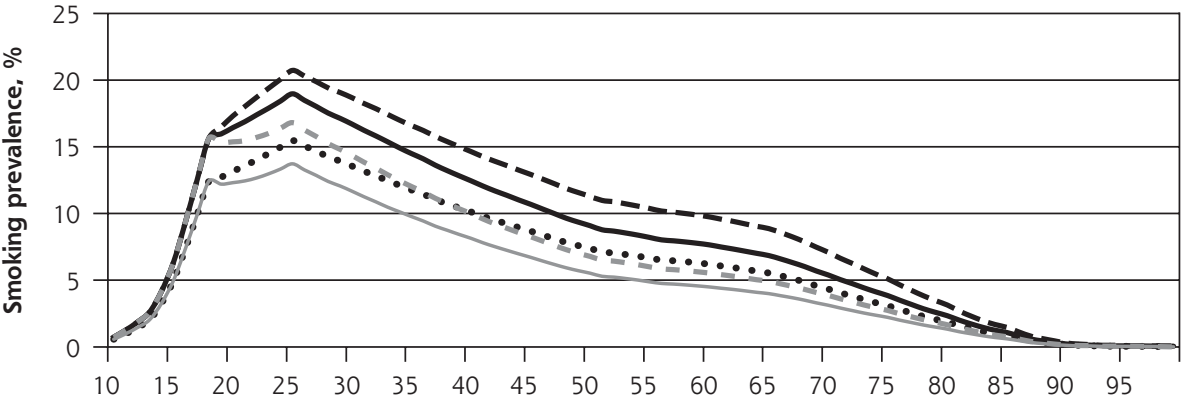

— Current counseling

- - - No counseling

..... Youth counseling

$--=$ Adult counseling

Youth and adult counseling combined

Age, years

Annual change in smoking-attributable fatalities

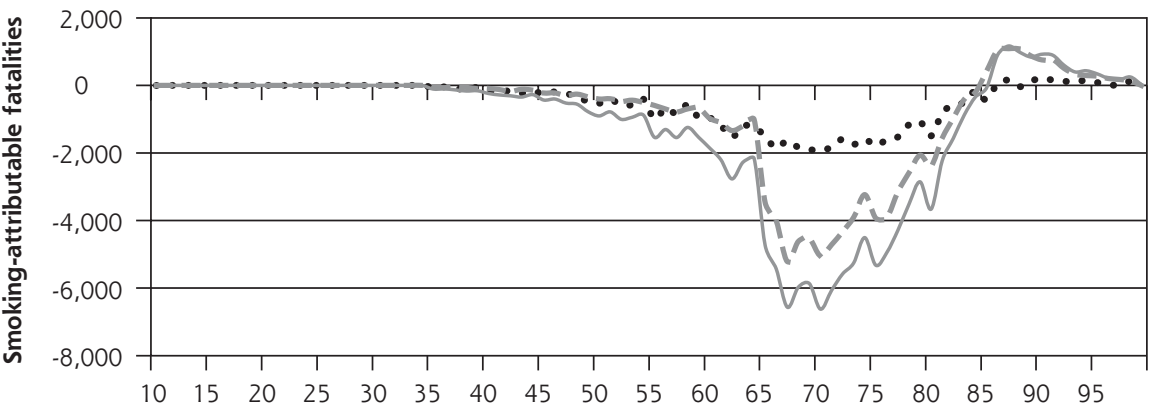

..... Youth counseling

- $-=$ Adult counseling

Youth and adult counseling combined

Age, years

Annual change in quality-adjusted life years

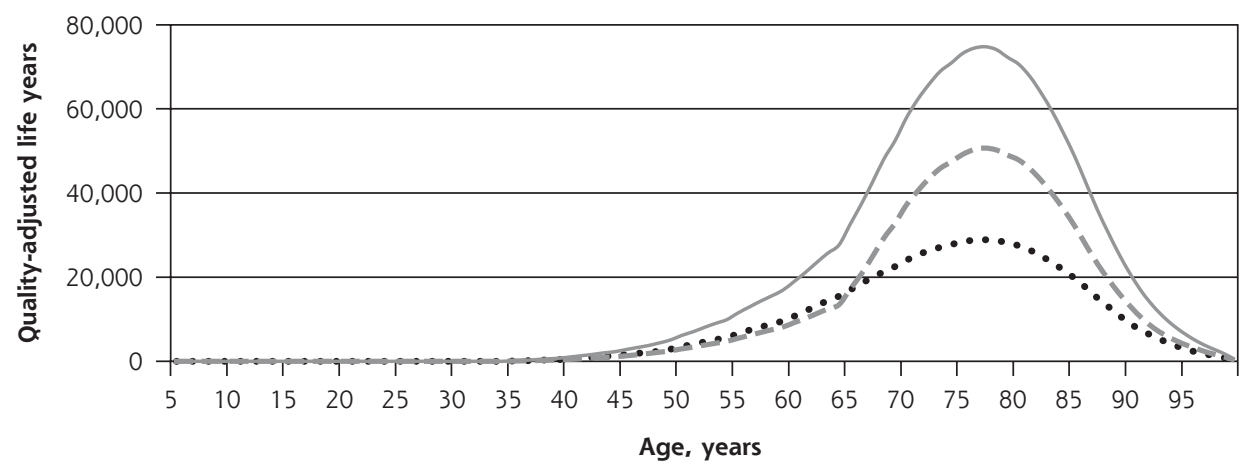

..... Youth counseling

- - - Adult counseling

Youth and adult counseling combined

Annual change in discounted net costs

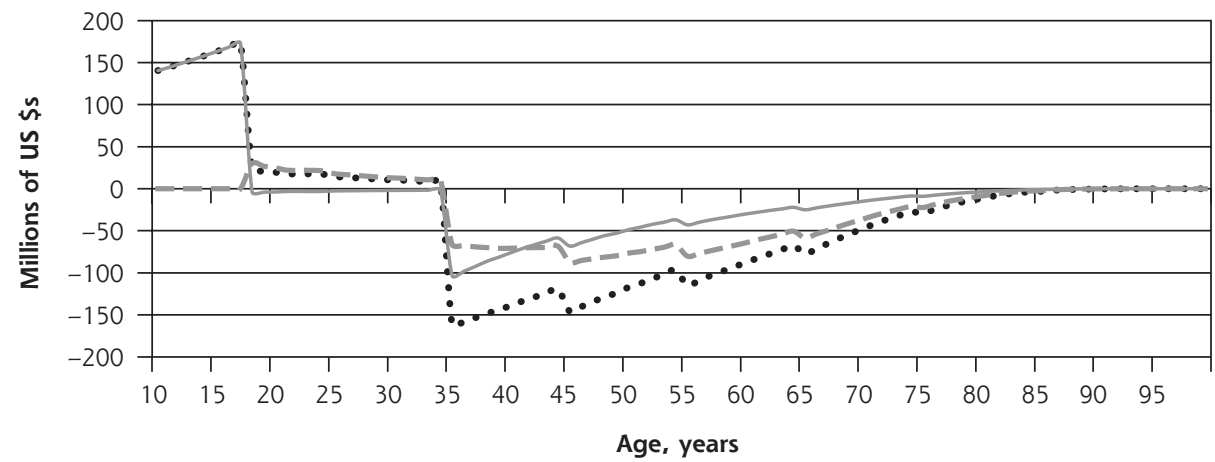

..... Youth counseling

--- Adult counseling

Youth and adult counseling combined

Note: Net costs include counseling, medication, and smoking-attributable medical costs. Stratified model inputs by age-group, including relative risks and costs, produce discontinuity in results reported by single year of age. 
later years; therefore, they are more heavily discounted than youth counseling costs.

Single-variable sensitivity analyses are shown in Figure 2. In multiple-variable sensitivity analysis for youth counseling, simultaneously changing counseling effectiveness, counseling costs, and smoking-attributable medical costs results in the clinical preventable burden ranging from 366,000 to $1,156,000$ QALYs saved

\section{Figure 2. Sensitivity analyses of youth and adult tobacco use counseling.}

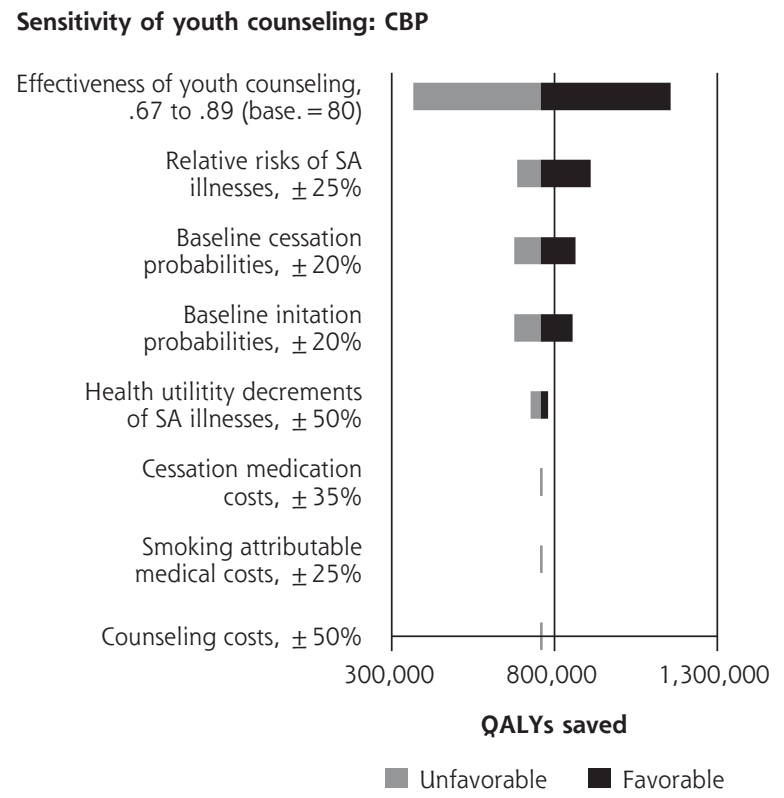

Sensitivity of adult counseling: CBP

Effectiveness of cessation medications, $\pm 50 \%$

Relative risks of SA illnesses, $\pm 25 \%$

Baseline initation probabilities, $\pm 20 \%$

Baseline cessation probabilities, $\pm 20 \%$

Health utilitity decrements of SA illnesses, $\pm 50 \%$

Cessation medication costs, $\pm 35 \%$

Smoking attributable medical costs, $\pm 25 \%$

$$
500,000
$$
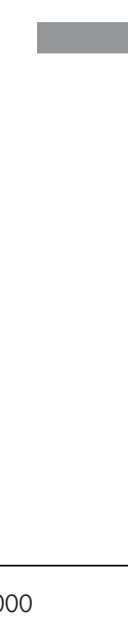

Sensitivity of youth counseling: CE ${ }^{\mathrm{a}}$

Effectiveness of youth counseling, .67 to .89

Counseling costs, $\pm 50 \%$

Smoking attributable medical costs, $\pm 25 \%$

Baseline initation probabilities, $\pm 20 \%$

Baseline cessation probabilities, $\pm 20 \%$

Cessation medication costs, $\pm 35 \%$

Health utilitity decrements of SA illnesses, ${ }^{b} \pm 50 \%$

Relative risks of SA illnesses, ${ }^{c} \pm 25 \%$

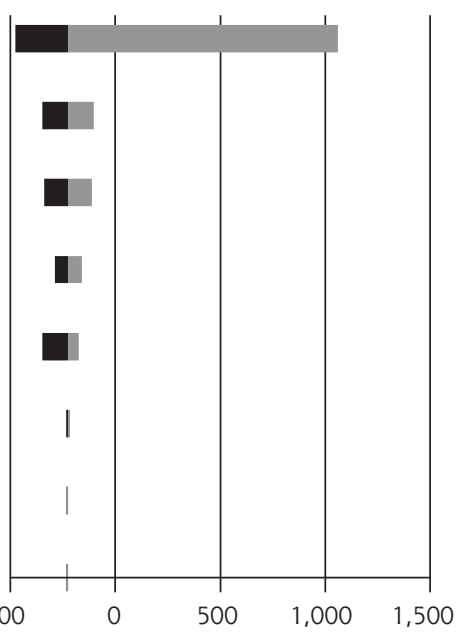

\$ saved per person or per QALY

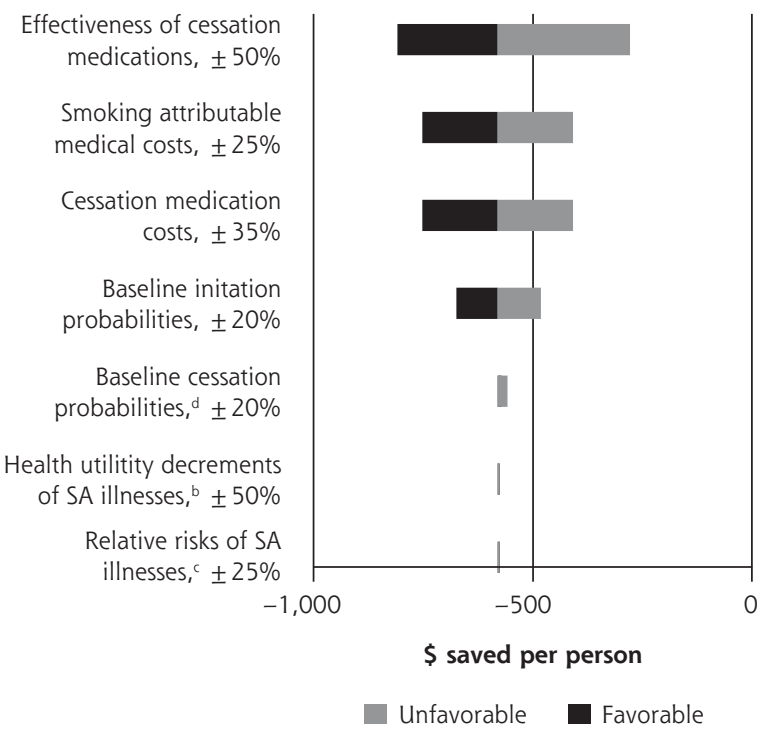

$\mathrm{CBP}=$ clinically preventable burden; $\mathrm{CE}=$ cost-effectiveness; $\mathrm{QALY}=$ quality-adjusted life year; $\mathrm{SA}=$ smoking-attributable.

a When net costs are negative, cost-effectiveness is expressed as net cost per person. When net costs are positive, cost-effectiveness is expressed as net cost per QALY.

${ }^{b}$ Net costs are expressed as per person; therefore, changes in utility values do impact the estimate of cost-savings.

' Disease risks and smoking costs are determined by smoking status independently from each other in the model. Changes to the risk of illness therefore do not impact cost-effectiveness.

${ }^{d}$ Complex interactions between changing baseline cessation probabilities and intervention effect on cessation probabilities affect smoking-attributable costs and expenditures on cessation medications in both the baseline and intervention scenarios. As result, the impact of changing baseline cessation probabilities on costeffectiveness is nonlinear. 
(base case $=757,000$ ). Simultaneously changing counseling effectiveness, counseling costs, and smokingattributable medical costs results in a cost-effectiveness range from $\$ 1,285$ saved per person to a net cost of $\$ 12,195 /$ QALY saved (base case $=\$ 225$ saved per person). In multiple-variable sensitivity analysis for adult counseling, simultaneously changing baseline youth initiation and medication effectiveness results in clinical preventable burden ranging from 519,000 to 1,694,000 QALYs saved (base case $=1,096,000$ ). Simultaneously changing smoking-attributable costs, baseline youth initiation, and medication effectiveness results in costeffectiveness ranging from $\$ 210$ to $\$ 1,676$ saved per person (base case $=\$ 580$ saved).

\section{DISCUSSION}

This article presents updated analysis of repeated counseling for adult cessation and the first analysis of the value of youth counseling in the context of a relative ranking. The results suggest that counseling youth not to start smoking and counseling adults to quit should be a high-priority use of clinician time. In Prevention Priorities, both receive the highest possible scores for both clinical preventable burden and cost-effectiveness and the highest total score. ${ }^{24}$ Only 6 services were cost saving. The clinical preventable burden of some common preventive services was considerably lower, including cervical cancer screening (268,000 QALYs saved), breast cancer screening $(164,000)$, influenza immunizations $(132,000)$, and tetanus, diphtheria, and acellular pertussis vaccination for adolescents and adults $(6,000)$.

We did not find that primary prevention (youth counseling) was more valuable than secondary prevention (adult counseling). Both are clearly of high value. Youth counseling is less effective at reducing initiation than adult counseling and medication are at increasing cessation; youth counseling is provided to all persons, whereas adult counseling is targeted to smokers; and on average, youth counseling costs are not as heavily discounted to present value in the cost-effectiveness calculation.

Our results are consistent with the literature, though few economic analyses of counseling assess annual counseling and include reductions in smokingattributable medical expenditures. Using a comparatively simple compartmental model, we previously found adult tobacco counseling to be a top-ranking service but with greater cost savings ( $\$ 842$ per person in 2012 US dollars) and a higher clinically preventable burden (2,473,000 QALYs saved). ${ }^{9}$ The microsimulation more accurately models the counterfactual of no counseling, leading to a lower clinical preventable burden and savings estimates. Feenstra et al estimated repeated brief interventions in the Dutch health care system. ${ }^{62}$ They found various low-intensity interventions for adults to be cost-effective but not cost saving. Eddy et al assessed brief intervention repeated over 10 years. They conservatively assumed each successive quit attempt had a lower success probability and included only the benefits of reducing cardiovascular disease, but they still found that intervention would cost only $\$ 3,000$ per QALY.10

To our knowledge, we report the first estimates of the health impact and cost-effectiveness of both youth counseling alone and the combined impact of youth and adult counseling. Wang and Michael estimated that a hypothetical $1 \%$ reduction in youth smoking prevalence would produce 99,000 additional QALYs and save $\$ 1.2$ billion over the lifetime of a cohort of students in $7^{\text {th }}$ to $12^{\text {th }}$ grades. ${ }^{63}$ Youth interventions based in the in community, such as school-based tobacco education, appear to be very cost-effective. ${ }^{64-67}$

Although consistent with the literature, our modeled estimates have meaningful limitations. First, the harms of secondhand smoke and deaths from smoking-caused residential fires are excluded. Second, the most recent Surgeon General's report identified additional risks of tobacco use not yet incorporated into our model: diabetes mellitus, rheumatoid arthritis, age-related macular degeneration, liver cancer, infant deaths, and failure of cancer treatment. ${ }^{2}$

We also did not account for electronic cigarettes because we had scarce data on their impact. Electronic cigarettes were the most frequently used tobacco product cited by middle- and high-school students in 2015. ${ }^{3}$ Excluding electronic cigarettes assumes that any health harms from their increased use is exactly offset by any benefit of reduced cigarette use. Neither did we assess whether pregnancy increases the probability of a sustained quit with or without clinician counseling, or the impact of restricted use of cessation medications during pregnancy.

Perhaps most importantly, the literature does not indicate whether the effectiveness of counseling remains constant. We assumed no change in effectiveness relative to no assistance, as repeated messages reinforce each other and aging smokers traverse stages of readiness to change. Our neutral assumption may overstate or understate the impact of repeated counseling. Also because of a lack of data, we assumed the use of smoking cessation medication among those newly counseled is the same as among those currently making quit attempts. If instead we assume no additional use of cessation medications, then both clinical preventable burden and cost savings of adult counseling would be nearly 50\% lower, and its Prevention Priorities total score would be reduced by 1 point. These uncertain- 
ties could be best addressed in long-term prospective studies of repeated counseling with careful recording of cessation medication use.

Despite limited precision, the results indicate that tobacco cessation counseling should be a highpriority use of clinic resources. Systems improvements may improve cessation counseling through standardized assessment forms ${ }_{1}^{68}$ electronic health record prompts, ${ }^{69,70}$ and provider feedback. ${ }^{71-73}$ In a comprehensive approach to implementing counseling guidelines with systems changes, Katz et al combined provider feedback, registering tobacco use as a vital sign, offering free nicotine-replacement therapy and proactive counseling. ${ }^{74}$ Observed continuous abstinence at 6 months in intervention sites was nearly 3 times higher than in control sites (10.9\% vs $3.8 \%)$.

Perceived low effectiveness of counseling may foster the impression that tobacco use is better addressed by community-based interventions. In an informal comparison, Bao et al found cessation advice to adults as provided in usual care and community-based interventions, such as tobacco taxes and clean indoor air laws, to have similar impact. ${ }^{75}$ Likewise, the $2.0 \%$ average reduction in smoking prevalence we estimated to occur when increasing smoking cessation counseling to all adult smokers from current levels is similar to that produced by community-based interventions assessed using the same simulation model for the Community Health Advisor. ${ }^{76}$ Moreover, it seems likely (though unproven) that the 2 strategies have synergistic effects, magnifying that of either alone.

Estimated cost savings from counseling suggest that meaningful investments in clinic systems to improve population health through tobacco cessation counseling are possible without increasing long-term health care costs. Of course, with the investments being borne by clinics in the short term and the savings accruing to various insurers years later, we cannot rely on the financial incentives from savings to make those investments happen. Payment systems that align financial incentives with the value of care system investments are necessary to realize the full potential of clinical tobacco cessation counseling. In the meantime, clinicians who wish to ensure their limited time with patients is well spent can be confident that evidence-based tobacco counseling can produce more meaningful improvements in population health with good stewardship of health care system resources than almost any other preventive service.

To read or post commentaries in response to this article, see it online at http://www.annfammed.org/content/15/1/37.

Key words: cigarette smoking; tobacco; counseling; cost-effectiveness; health impact; prioritization
Submitted September 9, 2016; submitted, revised, October 31, 2016; accepted November 18, 2016.

Funding support: Support for this study came from the Centers for Disease Control and Prevention (Cooperative Agreement Numbers 5H25PS003610 and U58/CC0322077-02-01), Robert Wood Johnson Foundation, WellPoint (now Anthem) Foundation, HealthPartners Institute for Education and Research, and American Heart Association.

Disclaimer: The contents are solely the responsibility of the authors and do not necessarily represent the official views of the Centers for Disease Control and Prevention.

Acknowledgments: We are grateful for the guidance of the National Commission on Prevention Priorities: Eduardo Sanchez, MD, MPH (Chair); Kim Barnhill, MS, MPH; Ross C. Brownson, PhD; Michael C. Caldwell, MD, MPH; Jonathan E. Fielding, MD, MPH, MBA; David W. Fleming, MD; Anne C. Haddix, PhD; George Isham MD; Lovell Jones, PhD; Warren A. Jones, MD, FAAFP; Linda Kinsinger, MD, MPH; Samuel Nussbaum, MD; C. Tracy Orleans, PhD; Marcel Salive, MD, MPH; Steven L. Solomon, MD; Kurt C. Stange, MD, PhD; Steven M. Teutsch, MD, MPH; Cristie Upshaw Travis, MS; Stephen Williams, MEd, MPA; and Steven H. Woolf, MD, MPH. We thank Nichol Edwards, MS, and Barbara Olson-Bullis, MA, for the expertise they provided in project guidance, literature review, and analysis.

Supplementary materials: Available at http://www.AnnFamMed. org/content/15/1/37/suppl/DC1/.

\section{References}

1. Centers for Disease Control and Prevention. Early Release of Selected Estimates Based on Data From the National Health Interview Survey, 2015. https://www.cdc.gov/nchs/data/nhis/earlyrelease/ earlyrelease201605_08.pdf. Published 2016.

2. US Department of Health and Human Services. The Health Consequences of Smoking-50 Years of Progress: A Report of the Surgeon General, 2014. Atlanta, GA: US Department of Health and Human Services, Centers for Disease Control and Prevention, National Center for Chronic Disease Prevention and Health Promotion, Office on Smoking and Health; 2014.

3. Singh T, Arrazola RA, Corey CG, et al. Tobacco use among middle and high school students-United States, 2011-2015. MMWR Morb Mortal Wkly Rep. 2016;65(14):361-367.

4. Siu AL; U.S. Preventive Services Task Force. Behavioral and pharmacotherapy interventions for tobacco smoking cessation in adults, including pregnant women: U.S. Preventive Services Task Force Recommendation Statement. Ann Intern Med. 2015;163(8):622-634.

5. Patnode CD, Henderson JT, Thompson JH, Senger CA, Fortmann SP, Whitlock EP. Behavioral counseling and pharmacotherapy interventions for tobacco cessation in adults, including pregnant women: a review of reviews for the U.S. Preventive Services Task Force. Ann Intern Med. 2015;163(8):608-621.

6. United States Preventive Services Task Force. Counseling to Prevent Tobacco Use and Tobacco-Caused Disease: Recommendation Statement. Rockville, MD: Agency for Healthcare Research and Quality; 2003.

7. Patnode CD, O'Connor E, Whitlock EP, Perdue LA, Soh C, Hollis J. Primary care-relevant interventions for tobacco use prevention and cessation in children and adolescents: a systematic evidence review for the U.S. Preventive Services Task Force. Ann Intern Med. 2013;158(4):253-260.

8. Moyer VA; U.S. Preventive Services Task Force. Primary care interventions to prevent tobacco use in children and adolescents: U.S. preventive services task force recommendation statement. Pediatrics. 2013;132(3):560-565. 
9. Solberg LI, Maciosek MV, Edwards NM, Khanchandani HS, Goodman MJ. Repeated tobacco-use screening and intervention in clinical practice: health impact and cost effectiveness. Am J Prev Med. 2006;31(1):62-71.

10. Eddy DM, Peskin B, Shcheprov A, Pawlson G, Shih S, Schaaf D. Effect of smoking cessation advice on cardiovascular disease. Am J Med Qual. 2009;24(3):241-249.

11. Kharbanda EO, Levine SB, Burstein GR. Delivering adolescent preventive services in an office setting. [xi.] [xi.]. Adolesc Med State Art Rev. 2011;22(3):482-497, xi.

12. Jaén $C R$, Stange KC, Nutting PA. Competing demands of primary care: a model for the delivery of clinical preventive services. J Fam Pract. 1994;38(2):166-171.

13. Jaén CR, Mcllvain H, Pol L, Phillips RLJ Jr, Flocke S, Crabtree BF. Tailoring tobacco counseling to the competing demands in the clinical encounter. J Fam Pract. 2001;50(10):859-863.

14. Solberg LI. Incentivising, facilitating, and implementing an office tobacco cessation system. Tob Control. 2000;9(Suppl 1):137-141.

15. Holtrop JS, Malouin R, Weismantel D, Wadland WC. Clinician perceptions of factors influencing referrals to a smoking cessation program. BMC Fam Pract. 2008;9:18.

16. Chernof BA, Sherman SE, Lanto AB, Lee ML, Yano EM, Rubenstein LV. Health habit counseling amidst competing demands: effects of patient health habits and visit characteristics. Med Care. 1999:37(8):738-747.

17. Krist AH, Shenson D, Woolf SH, et al. Clinical and community delivery systems for preventive care: an integration framework. Am J Prev Med. 2013;45(4):508-516.

18. DeVoe JE, Bazemore AW, Cottrell EK, et al. Perspectives in primary care: a conceptual framework and path for integrating social determinants of health into primary care practice. Ann Fam Med. 2016;14(2):104-108.

19. Solberg LI. Theory vs practice: should primary care practice take on social determinants of health now? No. Ann Fam Med. 2016;14(2):102-103.

20. Kaufman A. Theory vs practice: should primary care practice take on social determinants of health now? Yes. Ann Fam Med. 2016;14(2):100-101

21. Yarnall KS, Pollak KI, Østbye T, Krause KM, Michener JL. Primary care: is there enough time for prevention? Am J Public Health. 2003;93(4):635-641.

22. Østbye T, Yarnall KS, Krause KM, Pollak KI, Gradison M, Michener $\mathrm{JL}$. Is there time for management of patients with chronic diseases in primary care? Ann Fam Med. 2005;3(3):209-214.

23. Altschuler J, Margolius D, Bodenheimer T, Grumbach K. Estimating a reasonable patient panel size for primary care physicians with team-based task delegation. Ann Fam Med. 2012;10(5):396-400.

24. Maciosek MV, LaFrance AB, Dehmer SP, et al. Updated priorities among effective clinical preventive services. Ann Fam Med. 2017;15(1):14-22.

25. Gold MR, Siegel JE, Russell LB, Weinstein MC, eds. Cost-Effectiveness in Health and Medicine. New York, NY: Oxford University Press; 1996.

26. Fiore MC JC, Baker TB, Bailey WC, et al. Treating Tobacco Use and Dependence: 2008 Update. Rockville, MD: Agency for Healthcare Research and Quality;2008.

27. Centers for Disease Control and Prevention. Youth Risk Behavior Survey (YRBS). http://www.cdc.gov/healthyyouth/yrbs/index.htm. Published 2011. Accessed Feb 27, 2014.

28. National Center for Health Statistics. National Health Interview Survey, 2007. Hyattsville, Maryland: National Center for Health Statistics, Centers for Disease Control and Prevention; 2008.

29. Horner MJRL, Krapcho M, Neyman N, et al. Edwards BK. SEER Cancer Statistics Review, 1975-2006. http://seer.cancer.gov/ csr/1975_2006/. Published 2009. Accessed Apr, 122011.
30. DeFrances CJ, Hall MJ. 2002 National Hospital Discharge Survey. Adv Data. 2004;(342):1-29.

31. Centers for Disease Control and Prevention. Compressed Mortality File 1999-2006. CDC WONDER On-line Database, compiled from Compressed Mortality File 1999-2006 Series 20 No. 2L, 2009. http://wonder.cdc.gov/cmf-icd10.html. Accessed Dec 8, 2009.

32. Smoking-Attributable Mortality, Morbidity, and Economic Costs (SAMMEC): Adult SAMMEC and Maternal and Child Health (MCH) SAMMEC software. 2007. http://apps.nccd.cdc.gov/sammec/.

33. Chowdhury SMS, Wun L. Linking Medical Expenditure Panel Survey to the National Health Interview Survey: Weighting and Estimation. Working Paper No. 12005. Rockville, MD: Agency for Healthcare Research and Quality; 2012.

34. Levy D, Newhouse J. Assessing the effects of tobacco policy changes on smoking-related health expenditures. In: Bearman $\mathrm{P}$, Neckerman $\mathrm{K}$, Wright L, ed. After Tobacco: What Would Happen If Americans Stopped Smoking? New York: Columbia University Press; 2011:256-289.

35. Hockenberry JM, Curry SJ, Fishman PA, et al. Healthcare costs around the time of smoking cessation. Am J Prev Med. 2012;42(6): 596-601.

36. Centers for Disease Control and Prevention (CDC). Smokingattributable mortality, years of potential life lost, and productivity losses-United States, 2000-2004. MMWR Morb Mortal Wkly Rep. 2008;57(45):1226-1228.

37. Fishman PA, Khan ZM, Thompson EE, Curry SJ. Health care costs among smokers, former smokers, and never smokers in an HMO. Health Serv Res. 2003;38(2):733-749.

38. Fishman PA, Thompson EE, Merikle E, Curry SJ. Changes in health care costs before and after smoking cessation. Nicotine Tob Res. 2006;8(3):393-401.

39. Miller VP, Ernst C, Collin F. Smoking-attributable medical care costs in the USA. Soc Sci Med. 1999;48(3):375-391.

40. Martinson BC, O'Connor PJ, Pronk NP, Rolnick SJ. Smoking cessation attempts in relation to prior health care charges: the effect of antecedent smoking-related symptoms? Am J Health Promot. 2003;18(2):125-132.

41. Bauman KE, Ennett ST, Foshee VA, Pemberton M, King TS, Koch GG. Influence of a family program on adolescent smoking and drinking prevalence. Prev Sci. 2002;3(1):35-42.

42. Jackson C, Dickinson D. Enabling parents who smoke to prevent their children from initiating smoking: results from a 3-year intervention evaluation. Arch Pediatr Adolesc Med. 2006;160(1):56-62.

43. Ausems M, Mesters I, van Breukelen G, De Vries H. Short-term effects of a randomized computer-based out-of-school smoking prevention trial aimed at elementary schoolchildren. Prev Med. 2002;34(6):581-589.

44. Haggerty KP, Skinner ML, MacKenzie EP, Catalano RF. A randomized trial of Parents Who Care: effects on key outcomes at 24-month follow-up. Prev Sci. 2007;8(4):249-260.

45. Pbert L, Flint AJ, Fletcher KE, Young MH, Druker S, DiFranza JR. Effect of a pediatric practice-based smoking prevention and cessation intervention for adolescents: a randomized, controlled trial. Pediatrics. 2008;121(4):e738-e747.

46. Hovell MF, Slymen DJ, Jones JA, et al. An adolescent tobacco-use prevention trial in orthodontic offices. Am J Public Health. 1996;86 (12):1760-1766.

47. Curry SJ, Hollis J, Bush T, et al. A randomized trial of a familybased smoking prevention intervention in managed care. Prev Med. 2003;37(6 Pt 1):617-626.

48. Hollis JF, Polen MR, Whitlock EP, et al. Teen reach: outcomes from a randomized, controlled trial of a tobacco reduction program for teens seen in primary medical care. Pediatrics. 2005;115(4):981-989.

49. Fidler W, Lambert TW. A prescription for health: a primary care based intervention to maintain the non-smoking status of young people. Tob Control. 2001;10(1):23-26. 
50. Lando HA, Hennrikus D, Boyle R, Lazovich D, Stafne E, Rindal B. Promoting tobacco abstinence among older adolescents in dental clinics. J Smok Cessat. 2007;2(1):23-30.

51. Centers for Disease Control and Prevention (CDC). Quitting smoking among adults-United States, 2001-2010. MMWR Morb Mortal W/kly Rep. 2011;60(44):1513-1519.

52. Cahill K, Stevens S, Perera R, Lancaster T. Pharmacological interventions for smoking cessation: an overview and network metaanalysis. Cochrane Database Syst Rev. 2013;5(5):CD009329.

53. Meyer C, Ulbricht S, Baumeister SE, et al. Proactive interventions for smoking cessation in general medical practice: a quasirandomized controlled trial to examine the efficacy of computertailored letters and physician-delivered brief advice. Addiction. 2008;103(2):294-304.

54. Jamal A, Dube SR, Babb SD, Malarcher AM; Centers for Disease Control and Prevention (CDC). Tobacco use screening and cessation assistance during physician office visits among persons aged 11-21 years-National Ambulatory Medical Care Survey, United States, 2004-2010. MMWR Suppl. 2014;63(2):71-79.

55. Rand CM, Auinger P, Klein JD, Weitzman M. Preventive counseling at adolescent ambulatory visits. J Adolesc Health. 2005;37(2):87-93.

56. King BA, Dube SR, Babb SD, McAfee TA. Patient-reported recall of smoking cessation interventions from a health professional. Prev Med. 2013;57(5):715-717.

57. National Committee for Quality Assurance. Medical Assistance with Smoking and Tobacco Use Cessation. 2015. http://www.ncqa.org/ ReportCards/HealthPlans/StateofHealthCareQuality/2015TableofCont ents/SmokingCessation.aspx. Accessed Nov 9, 2015.

58. Ingenix. 2013 National Fee Analyzer. Eden Prairie, MN: OPTUMInsight; 2013.

59. US Bureau of Labor Statistics. May 2012 National Occupational Employment and Wage Estimates. http://www.bls.gov/oes/2012/ may/oes_nat.htm. Accessed Jun 3, 2015.

60. U.S. Bureau of Labor Statistics. Employer Costs for Employee Compensation. 2012; http://www.bls.gov/data/\#wages. Accessed March 25, 2013.

61. Age and Sex Composition in the United States: 2012, Table 1. https://www.census.gov/population/age/data/2012comp.html. Accessed April 29, 2016.

62. Feenstra TL, Hamberg-van Reenen HH, Hoogenveen RT, Ruttenvan Mölken MP. Cost-effectiveness of face-to-face smoking cessation interventions: a dynamic modeling study. Value Health. 2005;8(3):178-190.

63. Wang LY, Michael SL. Long-term health and medical cost impact of smoking prevention in adolescence. J Adolesc Health. 2015;56(2):160-166.
64. Wang LY, Gutin B, Barbeau P, et al. Cost-effectiveness of a schoolbased obesity prevention program. J Sch Health. 2008;78(12): 619-624.

65. Hoeflmayr D, Hanewinkel R. Do school-based tobacco prevention programmes pay off? The cost-effectiveness of the 'Smoke-free Class Competition'. Public Health. 2008;122(1):34-41.

66. Tengs TO, Osgood ND, Chen LL. The cost-effectiveness of intensive national school-based anti-tobacco education: results from the tobacco policy model. Prev Med. 2001;33(6):558-570.

67. Ross H, Powell LM, Bauer JE, Levy DT, Peck RM, Lee HR. Community-based youth tobacco control interventions: cost effectiveness of the Full Court Press project. Appl Health Econ Health Policy. 2006;5(3):167-176.

68. Milch CE, Edmunson JM, Beshansky JR, Griffith JL, Selker HP. Smoking cessation in primary care: a clinical effectiveness trial of two simple interventions. Prev Med. 2004;38(3):284-294.

69. McCullough A, Fisher M, Goldstein AO, Kramer KD, Ripley-Moffitt C. Smoking as a vital sign: prompts to ask and assess increase cessation counseling. J Am Board Fam Med. 2009;22(6):625-632.

70. Silfen SL, Farley SM, Shih SC, et al; Centers for Disease Control and Prevention (CDC). Increases in smoking cessation interventions after a feedback and improvement initiative using electronic health records - 19 community health centers, New York City, October 2010-March 2012. MMWR Morb Mortal Wkly Rep. 2014;63(41):921-924.

71. Andrews JO, Tingen MS, Waller JL, Harper RJ. Provider feedback improves adherence with AHCPR Smoking Cessation Guideline. Prev Med. 2001;33(5):415-421.

72. Amundson G, Solberg LI, Reed M, Martini EM, Carlson R. Paying for quality improvement: compliance with tobacco cessation guidelines. Jt Comm J Qual Saf. 2003;29(2):59-65.

73. Bentz CJ, Bayley KB, Bonin KE, et al. Provider feedback to improve $5 A^{\prime}$ 's tobacco cessation in primary care: a cluster randomized clinical trial. Nicotine Tob Res. 2007;9(3):341-349.

74. Katz DA, Muehlenbruch DR, Brown RL, Fiore MC, Baker TB; AHRQ Smoking Cessation Guideline Study Group. Effectiveness of implementing the agency for healthcare research and quality smoking cessation clinical practice guideline: a randomized, controlled trial. J Natl Cancer Inst. 2004;96(8):594-603.

75. Bao Y, Duan N, Fox SA. Is some provider advice on smoking cessation better than no advice? An instrumental variable analysis of the 2001 National Health Interview Survey. Health Serv Res. 2006;41(6):2114-2135.

76. Maciosek MV, Flottemesch TJ, Dehmer SP, LaFrance AB, McGree DA, O'Blenes SM. Community Health Advisor. 2015. http://www.communityhealthadvisor.org/cha3/. 